\title{
Zoning methodology for estimating the service life of the vehicle
}

\author{
Danila Ptitsyn $^{1 *}[0000-0003-4682-5799]$, Vladimir Ershov ${ }^{1[0000-0002-6189-0129]}$, Artem Podgornyy ${ }^{1[0000-}$ \\ 0003-2344-6112], and Alexey Akulov 10000-0001-8952-0237] \\ ${ }^{1}$ Moscow Automobile and Road Construction State Technical University, 125315, Leningradsky \\ prospect 64, Moscow, Russia
}

\begin{abstract}
The article presents a comprehensive method for removing uncertainty when solving multicriteria problems of vehicle maintenance. The task of the control system for the service life of the car is formed, and its characteristics are also highlighted. The main provisions of the zoning method are formulated from the point of view of the hierarchical correlation of the probabilities of the state of the external environment. The dynamics of changes in the quality indicators of cars in a multicriteria setting is estimated.
\end{abstract}

Keywords: vehicle service life, control system operation, quality parameter, integrated method.

\section{Introduction}

Multi-criteria in assessing the service life of a car is a direct consequence of the incompleteness of information about the situation, determined by a set of factors that must be considered when making decisions in the complex of technical operation of vehicles (TOV). It is because of the lack of sufficiently complete and reliable information necessary for making reliable decisions on maintenance and repair throughout the entire life of the vehicle, it is impossible to unambiguously determine the nature of the operations carried out, which gives rise to the need to develop an analytical apparatus that optimizes the decision made according to several performance indicators, considering possible changes in the operating conditions of the vehicle[1-3]. Based on various options for decision-making methods in conditions of uncertainty and methods for solving multi-criteria problems, it is possible to formulate a comprehensive method for removing uncertainty when solving multi-criteria problems, which makes it possible to increase the reliability of decisions made in information situations typical for a vehicle service life management system (VSLMS).

The multicriteria problem of optimizing the development of solutions for VSLMS can be formed as follows, in view of its characteristics by means of 3 concepts:

1) many possible solutions in VSLMS;

2) a set of information states (IS) of VSLMS;

3 ) the effectiveness of any decision for each information state of the VSLMS.

\footnotetext{
${ }^{*}$ Corresponding author: d.pticyn@madi.ru
} 
When solving the problem of operating cars in conditions of uncertainty in the environment, it is necessary to develop a method for «on-line analysis of the indicator of unscheduled maintenance», which will significantly reduce the flow of random failures.

\section{Materials and methods}

Let us formulate the main provisions of the zoning method according to the principle of observing the hierarchical ratio of the probabilities of possible states of the external environment [4-10]. The proposed solution to multicriteria problems, determined by individual IS's that change during the operation of a vehicle in VSLMS, is based on the zoning method. The method consists in splitting the set of possible states of «nature» into subsets of the dominance of individual actions. In a number of cases, the use of this method does not allow obtaining the desired optimal solution, although it greatly simplifies its search. This circumstance determined the direction of development of this method in a number of directions.

1. Zoning is an inverse parametric linear programming problem, therefore, to obtain the desired solution, it is important to choose a zoning method [11].

2. Matrix game with «nature» is reduced (provided that the function of efficiency indicators from changes in the vector of the state of nature is continuous) to a linear problem of vector optimization and vice versa [12]. Therefore, to solve games with nature, vector optimization methods can be used, and multicriteria problems in many cases can be solved using the apparatus of the theory of games with «nature».

3. When passing from a multicriteria problem to problems of games with «nature», the probabilities of states of nature $p j$ are, in their meaning, adequate to the coefficients of the relative importance of the criteria $c_{j}$, i.e. $p_{j} \equiv c_{j}$.

4. The method is aimed at studying the phenomena of the external environment of vehicle operation, which are caused by individual IS VSLMS [13, 14].

5. It is advisable to make zoning not according to the principle of domination of individual actions, but according to the principle of preserving a given hierarchical ratio of possible states of «nature» or IS VSLMS [15].

During the operation of the car, when it reaches the limit state, or if its technical parameters do not correspond to the normative values of constructive or environmental safety, determined by the requirements of the external environment at a certain stage of operation, various strategies for restoring the state of the car are possible $\left(S_{1}, S_{2}, S_{3} \ldots S_{n}\right)$. The operating company can either write off the car upon reaching the limiting state according to some criterion, or, by means of technical influences (maintenance or major overhaul), raise the reduced value of the quality indicator (coefficient of technical utilization - COU) to the required level, while increasing the cost of its operation. In any case, an analytical apparatus is needed that allows the management of quality indicators in the TOV process [16-18]. Let us consider the possible dynamics of the change in the COU of a car, depending on the mileage from the beginning of its operation, in several variants. Fig. 1 shows the most general of the possible options for changing the values of the COU depending on the mileage of the car. 


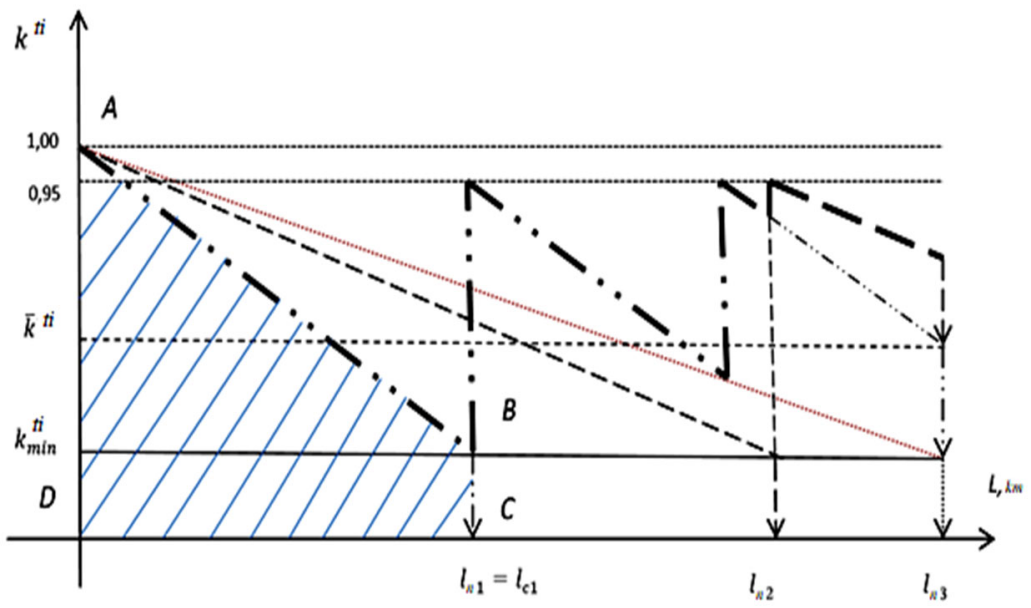

Fig. 1. The general case of change in the values of COU depending on the car mileage.

It has been proven that the change in the values of the COU, depending on the vehicle mileage from the beginning of operation, occurs according to a linear law [3]. Let us introduce the designations: $k_{\text {min }}^{t i}$ is the minimum possible (limiting) value of the COU; $l_{\mathrm{n} 1}$, $l_{\mathrm{n} 2}, l_{\mathrm{n} 3}$, are vehicle mileages, at which the limiting values are reached; $k^{t i}$ - realizable indicator of the quality of the car; 0.95 (close to 1.0) is the COU value, up to which the parameter is restored under technical influences. In the general case [19], the equation for the dependence of the COU obeys a linear law:

$$
k_{i}^{t i}(L)=\left(\frac{k_{\min }^{t i}-1}{l_{i}}\right) L+1
$$

where $k_{\text {min }}^{t i}$ is the minimum allowable value of the COU for a separate criterion.

The first case of a possible operation strategy $\left(\mathrm{S}_{1}\right)$, when the car is written off when it reaches the limit state and its further operation is not permissible. At the same time, the car constantly passed routine maintenance-1 and maintenance-2, at which the necessary accompanying major overhaul was produced according to the standard (in Fig. $1-l_{\mathrm{n} 1}, \mathrm{~km}$ ).

Let's consider a trapezoid $S_{A B C D}$. In general terms, the area of a trapezoid is defined as:

$S_{A B C D}=\int_{0}^{l_{n 1}}\left(\frac{k_{\min }^{t i}-1}{l_{\mathrm{H} 1}} \cdot l+1\right) d l=\int_{0}^{l_{n 1}}\left(\frac{k_{\min }^{t i}-1}{l_{\mathrm{H} 1}}\right) d l+\int_{0}^{l_{n 1}} d l=\left(\frac{k_{\min }^{t i}-1}{l_{\mathrm{H} 1}}\right) \cdot \frac{l_{n 1}^{2}}{2}+l_{n 1}$

And as for a linear dependence:

$$
S_{A B C D}=\frac{1}{2}\left(1-k_{m i n}^{t i}\right) \cdot l_{n 1}+k_{m i n}^{t i} \cdot l_{n 1}=\frac{1}{2}\left(1+k_{m i n}^{t i}\right) \cdot l_{\mathrm{H} 1}=\frac{k_{m i n}^{t i}+1}{2} \cdot l_{n 1},
$$

Then:

$$
S_{A B C D}=\frac{k_{m i n}^{t i}+1}{2} \cdot l_{n 1} .
$$

Next, we determine the value of the car's COU being implemented for one arbitrary criterion:

$$
\bar{k}^{t i}=\frac{S_{A B C D}}{l_{n 1}}=\frac{\left(\frac{k_{\min }^{t i}+1}{2} \cdot l_{n 1}\right)}{l_{n 1}},
$$


where $\bar{k}^{t i}$ is realizable indicator of the quality of the car;

$$
\bar{k}_{(1)}^{t i}=\frac{k_{\min }^{t i}+1}{2}
$$

The carried-out study of the first case of the operation strategy allows us to conclude that the values of the implemented COU are determined by its minimum permissible value. The second case of the operation strategy $\left(\mathrm{S}_{2}\right)$ - the car is removed from the line when it is necessary to restore the operability of a faulty unit, assembly or part. In this case, the value of the COU should be restored to a value close to the original $k^{t i}=k_{n}^{t i}$ (Fig. 2). This situation arises when an unscheduled major overhaul is carried out in the event of an emergency with any structural element of the vehicle.

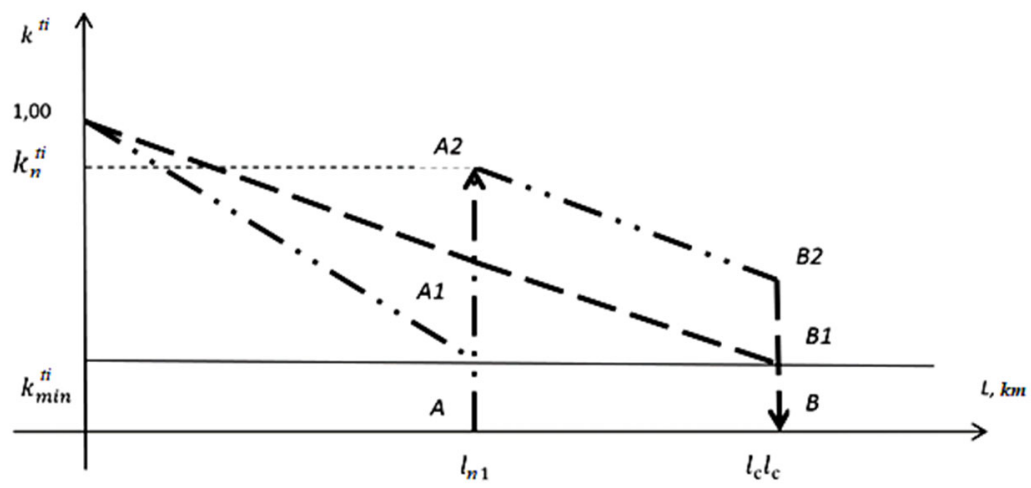

Fig. 2. Improving the quality indicator to prolong the vehicle's working condition according to one of the criteria.

Initially, we will set the value of $k^{t i}$ at $l_{n 1}$. Let's determine the area of the figure:

$$
S_{A_{1} A_{2} B_{2} B_{1}}=S_{A A_{2} B_{2} B}-S_{A A_{1} B_{1} B}
$$

and make a number of transformations:

$$
\begin{gathered}
S_{A_{1} A_{2} B_{2} B_{1}}=\frac{\left|A A_{2}\right|+\left|B B_{2}\right|}{2} \cdot|A B|-\frac{\left|A A_{1}\right|+\left|B B_{1}\right|}{2} \cdot|A B| \\
S_{A_{1} A_{2} B_{2} B_{1}}=\left(\left|A A_{2}\right|+\left|B B_{2}\right|-\left|A A_{1}\right|+\left|B B_{1}\right|\right) \cdot \frac{|A B|}{2}=2 \cdot\left|A A_{2}\right| \cdot \frac{|A B|}{2},
\end{gathered}
$$

Then

$$
S_{A_{1} A_{2} B_{2} B_{1}}=\left|A_{2} A_{1}\right| \cdot|A B| .
$$

Continuing transformations, we obtain

$$
\begin{gathered}
\left|A_{2} A_{1}\right|=\mathrm{A}_{2}-\mathrm{A}_{1}=k_{n}^{t i}-\left(k_{\min }^{t i}-1\right) \cdot \frac{l_{n 1}}{l_{c}}-1, \\
|A B|=l_{c}-l_{n 1}
\end{gathered}
$$

Then

$$
\begin{gathered}
S_{A_{1} A_{2} B_{1} B_{2}}=\left[k_{n}^{t i}-\left(k_{\text {min }}^{t i}-1\right) \cdot \frac{l_{n 1}}{l_{c}}-1\right] \cdot\left(l_{c}-l_{n 1}\right) \\
S_{A_{1} A_{2} B_{1} B_{2}}=k_{n}^{t i} l_{c}-\left(k_{\text {min }}^{t i}-1\right) l_{n 1}-l_{c}-k_{n}^{t i} l_{n 1}+\left(k_{\text {min }}^{t i}-1\right) \frac{\left(l_{n 1}\right)^{2}}{l_{c}}+l_{n 1}
\end{gathered}
$$

Thus, 


$$
f\left(l_{n}\right)=S_{A_{1} A_{2} B_{1} B_{2}}=k_{n}^{t i} l_{c}-\left(k_{\text {min }}^{t i}-1\right) l_{n 1}-l_{c}-k_{n}^{t i} l_{n 1}+\left(k_{\text {min }}^{t i}-1\right) \frac{\left(l_{n 1}\right)^{2}}{l_{c}}+l_{n 1} .
$$

Let's define that

Hereof

$$
f^{\prime}\left(l_{n}\right)=-\left(k_{\text {min }}^{t i}-1\right) l_{n 1}-k_{n}^{t i}+2\left(k_{\text {min }}^{t i}-1\right) \frac{l_{n 1}}{l_{c}}+1=0
$$

$$
l_{\mathrm{H}}=\frac{\left(k_{\text {min }}^{t i}+k_{n}^{t i}-2\right) \cdot l_{c}}{2\left(k_{\text {min }}^{t i}-1\right)} .
$$

Then, when the vehicle is restored to the value $k^{t i}=k_{n}^{t i}$, for the case of a possible operation strategy $\left(\mathrm{S}_{1}\right)$, when the car is removed from the line for decommissioning, the mileage can be taken equal to:

$$
l_{n 1}=\frac{l_{c}}{2}
$$

Let us determine the value of the quality indicator $\left(k^{t i}\right)$, with $l=l_{n 1}$ :

$$
\begin{gathered}
k^{t i}\left(l_{n}\right)=\frac{k_{\text {min }}^{t i}-1}{l_{c}} \cdot l_{n 1}+1=\frac{k_{\text {min }}^{t i}-1}{l_{c}} \cdot \frac{\left(k_{\text {min }}^{t i}+k_{n}^{t i}-2\right) \cdot l_{c}}{2\left(k_{\text {min }}^{t i}-1\right)}+1=\frac{k_{\text {min }}^{t i}+k_{n}^{t i}-2}{2}+1 \\
k^{t i}\left(l_{n 1}\right)=\frac{k_{\text {min }}^{t i}+k_{n}^{t i}}{2} .
\end{gathered}
$$

If the value $k_{n}^{t i}=1$, then

$$
k^{t i}\left(l_{n 1}\right)=\frac{k_{\min }^{t i}+1}{2} .
$$

Consequently, the value of the quality indicator in this case, as well as in the first case, depends on the minimum value of the COU [20].

Next, we determine the value of the realized quality indicator $\bar{k}^{t i}{ }_{(2)}$ (the average value of the quality indicator for a certain period of vehicle operation). For this, we will present one more graph (Fig. 3).

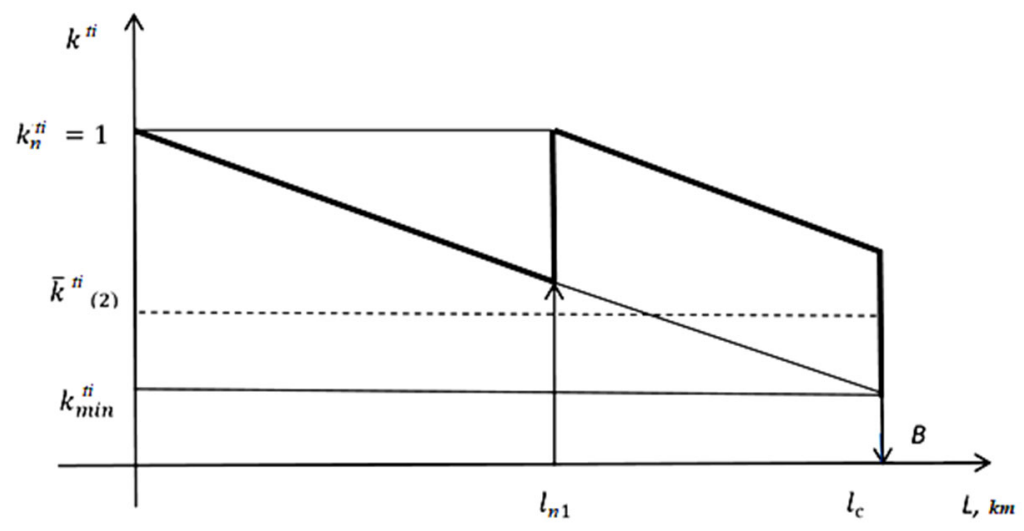

Fig. 3. Determination of the realizable quality indicator $\bar{k}^{t i}$.

$$
\bar{k}_{(2)}{ }^{t i}=\frac{\left[\frac{1+\left(\frac{k_{\min }^{t i}+1}{2}\right)}{2} \cdot \frac{l_{c}}{2}\right] \cdot 2}{l_{c}}=\frac{3+k_{\text {min }}^{t i}}{4} .
$$


Thus,

$$
\bar{k}_{(2)}{ }^{t i}=\frac{3+k_{\min }^{t i}}{4}
$$

Let us compare the obtained value of $\bar{k}_{(2)}^{t i}$ with the value $\bar{k}_{(1)}^{t i}$.

$$
\begin{gathered}
\Delta \bar{k}=\bar{k}_{(2)}^{t i}-\bar{k}_{(1)}^{t i}=\frac{3+k_{\min }^{t i}}{4}-\frac{k_{\min }^{t i}+1}{2}=\frac{1-k_{\min }^{t i}}{4} \\
\Delta \bar{k}=\frac{1-k_{\min }^{t i}}{4} .
\end{gathered}
$$

The third case of a possible strategy $\left(\mathrm{S}_{3}\right)$. There comes a limiting state of the car according to one of the indicators (a number of indicators) during the run $l_{\mathrm{n} 1}$. A decision is made to restore all the properties of the car, including technical interventions to maintain the overall performance of the car to the initial value $k^{t i}=1$, or close to the original $k^{t i}=k_{n}^{t i}$ (Fig. 4). As a rule, this is the major overhaul of the basic units and mechanisms of the engine, the support system, vehicle control systems, etc.

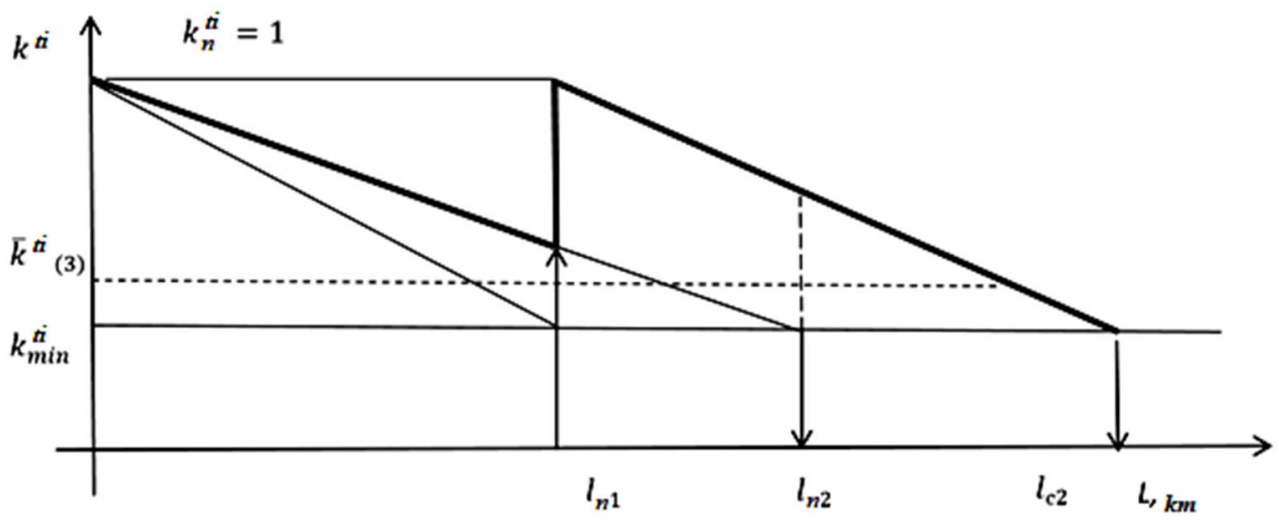

Fig. 4. Implemented quality indicator (third strategy)

Let us define in this case the value of the realized indicator of the quality of the car:

$$
\begin{gathered}
\bar{k}_{(3)}^{t i}=\frac{\left[\frac{1+\left(\frac{k_{\min }^{t i}+1}{2}\right)}{2} \cdot \frac{l_{c}}{2}+\left(\frac{k_{\min }^{t i}+1}{2}\right) \cdot l_{c}\right]}{\frac{3 l_{c}^{2}}{2}}=\frac{5 k_{\min }^{t i}+7}{2} . \\
\bar{k}_{(3)}^{t i}=\frac{5 k_{\min }^{t i}+7}{2} .
\end{gathered}
$$

\section{Results and discussion}

The considered spectrum of the strategy from the possible $\left(S_{1}, S_{2}, S_{3} \ldots S_{p}\right)$, when realizing the quality of the car, considering various cases of the onset of the limiting state and possible moments of decommissioning the car is presented in Table 1. 
Table 1. The value of the realizable indicator of the quality of the car under various strategies for restoring its technical condition.

\begin{tabular}{|l|c|}
\hline \multicolumn{1}{|c|}{$S_{p}$} & $\bar{k}_{(j)}^{t i}$ \\
\hline $\begin{array}{l}S_{1} \text { is the case when car is removed from the line for } \\
\text { decommissioning when the limit state is reached according to the } \\
\text { standard indicator and its further operation is unacceptable }\end{array}$ & $\bar{k}_{(1)}^{t i}=\frac{k_{\text {min }}^{t i}+1}{2}$ \\
\hline $\begin{array}{l}S_{2} \text { is the case when car is removed from the line if it is necessary } \\
\text { to restore the functionality of a faulty car of a unit, unit or part }\end{array}$ & $\bar{k}_{(2)}^{t i}=\frac{3+k_{\text {min }}^{t i}}{4}$ \\
\hline $\begin{array}{l}S_{3} \text { is the case when the limiting state of the car occurs according } \\
\text { to one of the indicators (a number of indicators). A decision is } \\
\text { made to restore all the properties of the car, including technical } \\
\text { interventions to maintain the overall performance of the car to its } \\
\text { original value }\end{array}$ & $\bar{k}_{(3)}^{t i}=\frac{5 k_{\text {min }}^{t i}+7}{2}$. \\
\hline
\end{tabular}

In the course of the study, in each case, $\left(k_{\min }^{t i}, l_{j}, \bar{k}_{(j)}^{t i}\right)$ and, also $\Delta \bar{k}$ were determined. The results obtained can be used to identify:

1) determination of analytical links between various strategies of vehicle operation $\left(S_{1}\right.$, $S_{2}, S_{3} \ldots S_{p}$ ), when predicting the implementation of the quality of the vehicle over time (operational properties, including structural and environmental safety), considering various cases of loss of performance;

2) the dynamics of changes in the values of the realized indicator of the quality of the $\operatorname{car}\left(\bar{k}_{(j)}^{t i}\right)$ according to separate criteria depending on the mileage since the start of the vehicle operation. The analysis performed in the second chapter showed that solving the problem of determining the service life of a car, considering the provision of modern standards and restrictions formed by the external environment of its operation, requires optimization of the decisions made in conditions of multi-criteria. This requires the formation of a multi-criteria structure of quality indicators, reflecting a number of required operational properties of the vehicle. The use of high-quality engineering materials also has a significant impact on the operation process, examples of which are given in [21-25].

In this case, the optimal vehicle mileage is determined in a multicriteria dynamic system with discrete states of maintenance and the corresponding IS`s. The results obtained are entered into the VSLMS statistical database at the operation stage, which in turn is the initial data for further planning the service life of a car of this brand.

\section{Conclusion}

In the course of the study, a method was developed for «operational analysis of the unscheduled current repair indicator» of a car, which allows: to determine the points of change in the intensity of the increment of the investigated indicator for each car individually; compare the indicators of maintenance and repair for the same maintenance intervals of various car models within their class; develop recommendations on the value of the indicator the effective service life of the vehicle for individual quality criteria. The use of this method is advisable to determine the value of the vehicle's interval availability factor, which can be interpreted as the probability that the vehicle will be in working condition at a specific time during a given maintenance interval. 


\section{References}

1. A. Terentyev, M. Karelina, A. Pavlovskaya, I. Arifullin, E. Karelina, Methodological approach to digitalization of management processes in automobile and road complex, IOP Conference Series: Materials Science and Engineering, 832, 1 (2020) DOI: 10.1088/1757-899X/832/1/012069

2. A. Terentyev, M. Karelina, S. Benevolenskiy, I. Arifullin, E.Karelina, Application of methods for obtaining pareto set for increasing effectiveness of managing decisions under conditions of multi-criteriality, Smart Innovation, Systems and Technologies, 172 DOI: 10.1007/978-981-15-2244-4_84

3. V. Moiseev, A. Terentyev, V. Rogov, E. Karelina, Methods for removing uncertainty in multi-criteria problems of effectiveness evaluation of decision-making, Journal of Physics: Conference Series, 1353, 1 (2019) DOI: 10.1088/1742-6596/1353/1/012100

4. A. Terentyev, M. Karelina, T. Cherepnina, D. Linnik, Digital object-oriented control models in automobile-road complex systems, IOP Conference Series: Materials Science and Engineering, 8321(2020) DOI: 10.1088/1757-899X/832/1/012058

5. I. Ivanov, A. Terentyev, S. Evtukov, Digital platform and ecosystem for providing regional transport mobility, Transportation Research Procedia, 50 (2020) DOI: 10.1016/j.trpro.2020.10.026

6. K. Taysayev, A. Terentyev, S. Evtukov, I. Arifullin, Efficiency ratio assessment model for buses, Transportation Research Procedia, 50 (2020) DOI: 10.1016/j.trpro.2020.10.079

7. S. Evtiukov, M. Karelina, A. Terentyev, A method for multi-criteria evaluation of the complex safety characteristic of a road vehicle, Transportation Research Procedia, 36 (2018) DOI: 10.1016/j.trpro.2018.12.057

8. A. Afanasev, A. Egoshin, S. Alekseev, Justification of logistical approach application in road safety management, IOP Conference Series: Earth and Environmental Science, 1947 (2018) DOI: 10.1088/1755-1315/194/7/072001

9. A. Marusin, A. Marusin, I. Danilov, A method for assessing the influence of automated traffic enforcement system parameters on traffic safety, Transportation Research Procedia, 36 (2018) DOI: 10.1016/j.trpro.2018.12.136

10. S. Porru, F. Misso, F. Pani, C. Repetto, Smart mobility and public transport: Opportunities and challenges in rural and urban areas, Journal of Traffic and Transportation Engineering (English Edition), 71 (2020) DOI: 10.1016/j.jtte.2019.10.002

11. R. Safiullin, M. Kerimov, A. Afanasyev, A. Marusin, A model for justification of the number of traffic enforcement facilities in the region, Transportation Research Procedia, 36 (2018) DOI: 10.1016/j.trpro.2018.12.135

12. S. Repin, S. Evtiukov, S. Maksimov, A method for quantitative assessment of vehicle reliability impact on road safety, Transportation Research Procedia, 36 (2018) DOI: 10.1016/j.trpro.2018.12.128

13. R. Safiullin, A. Marusin, R. Safiullin, T. Ablyazov, Methodical approaches for creation of intelligent management information systems by means of energy resources of technical facilities, E3S Web of Conferences, 140 (2019) DOI: 10.1051/e3sconf/201914010008

14. G. Ginzburg, S. Evtiukov, I. Brylev, S. Volkov. Reconstruction of Road Accidents Based on Braking Parameters of Category L3 Vehicles, Transportation Research Procedia, 20 (2017) DOI: 10.1016/j.trpro.2017.01.054

15. E. Kurakina, S. Evtiukov, J. Rajczyk, Forecasting of road accident in the DVRE system, Transportation Research Procedia, 36 (2018) DOI: 10.1016/j.trpro.2018.12.111 
16. A. Pushkarev, N. Podoprigora, V. Dobromirov, Methods of providing failure-free operation in transport infrastructure objects, Transportation Research Procedia, 36 (2018) DOI: 10.1016/j.trpro.2018.12.140

17. D. Skorokhodov, Y. Seliverstov, S. Seliverstov, I. Burov, E. Vydrina, N. Podoprigora, N. Shatalova, A. Cheremisina, Using Augmented Reality Technology to Improve the Quality of Transport Services, Communications in Computer and Information Science, 1140 (2020)

18. M. Karelina, A. Terentyev, V. Moiseev, V. Stroev, Method of Multi-Criteria Estimation of Agro-Industrial Complex Vehicles, in proceedings of the International Conference Topical Problems of Philology and Didactics: Interdisciplinary Approach in Humanities and Social Sciences (2019) DOI: 10.2991/tphd-18.2019.56

19. B. Agarski, I. Budak, B. Kosec, J. Hodolic, An Approach to Multi-criteria Environmental Evaluation with Multiple Weight Assignment, Environmental Modeling\& Assessment, 17, 3 (2011) DOI: 10.1007/s10666-011-9294-y

20. V. Guzman, A. Masegosa, D. Pelta, J. Verdegay, Fuzzy models and resolution methods for covering location problems: an annotated bibliography, Int. J. Unc. Fuzz. Knowl. Based Syst., 244 (2016) DOI:10.1142/S0218488516500276

21. A. Moradi, A. Etebarian, A. Shirvani, Soltani, Development of a fuzzy model for Iranian marine casualties management, J. Fuzzy. Set. Valued Anal. 00186, (2014) DOI: 10.5899/2014/JFSVA-00186

22. S. R. Abid, G. Murali, M. Amran, N. Vatin, R. Fediuk, M. Karelina, Evaluation of mode ii fracture toughness of hybrid fibrous geopolymer composites, Materials, 142 (2021) DOI: $10.3390 / \mathrm{ma} 14020349$.

23. S. Avudaiappan, Flores E. L. Saavedra, G. Araya-Letelies, W. J. Thomas, S. N. Raman, G. Murali, M. Amran, M. Karelina, R. Fediuk, N. Vatin, Experimental investigation on composite deck slab made of cold-formed profiled steel sheeting, Metals, 11, 229 (2021) DOI: $10.3390 /$ met11020229

24. M. Lukin, E. Prusov, S. Roshchina, M. Karelina, N. Vatin. Multi-span composite timber beams with rational steel reinforcement, Buildings, 1146 (2021) DOI: 10.3390/buildings 11020046

25. A. Korolev, M. Mishnev, D. Zherebysov, N. Vatin, M. Karelina, Polymers under load and heating deformability: modelling and predicting, Polymers, 13, 428 (2021) DOI: 10.3390/polym13030428 